06;07

\title{
Углеродная наноструктура для термоэлектрического генератора
}

\author{
(C) М.К. Рабчинский ${ }^{1}$, Е.Д. Эйдельман ${ }^{1,2, \llbracket, ~ А . Я . ~ В и н о г р а д о в ~}{ }^{1}$, С.А. Грудинкин ${ }^{1}$, А.Т. Дидейкин ${ }^{1}$ \\ ${ }^{1}$ Физико-технический институт им. А.Ф. Иофффе РАН, \\ Санкт-Петербург, Россия \\ ${ }^{2}$ Санкт-Петербургский государственный химико-фрармацевтический университет, \\ Санкт-Петербург, Россия \\ ^E-mail: Eidelman@mail.ioffe.ru
}

Поступило в Редакцию 7 декабря 2018 г.

В окончательной редакции 21 декабря 2018 г.

Принято к публикации 11 января 2019 г.

\begin{abstract}
Показано, что технологически возможно получение пленок из графитоподобного материала, пригодных для создания термоэлектрического генератора. Могут быть обеспечены однородность и довольно малая толщина такой пленки, а также ее размещение на алмазоподобной пленке с нанесенными контактами при приемлемом интерфейсе. Измерения показывают, что эффект увлечения обеспечивает значения термоэдс, примерно в 100 раз бо́льшие, чем диффузионный процесс. Размещение графитоподобного материала на алмазоподобной пленке также обеспечивает рост значения термоэдс. В этом проявляется эффект баллистического увлечения электронов фононами. Установлено, что могут быть достигнуты условия, необходимые для создания термоэлектрического генератора на базе углеродных наноструктур.
\end{abstract}

DOI: 10.21883/PJTF.2019.07.47534.17630

В настоящее время активно ведутся исследования термоэлектрических свойств графитоподобных пленок пленок углеродных материалов с $s p^{2}$-гибридизацией атомов углерода, а также их возможного применения для создания термоэлектрического генератора (ТЭГ) [1-3]. Изучались и различные аспекты эффекта увлечения электронов фононами - эффекта Гуревича — в углеродных материалах. Однако вклад данного эффекта не превышает типичных значений для вклада диффузии и составляет около $50 \mu \mathrm{V} \cdot \mathrm{K}^{-1}[1,2,4,5]$ в лучших из существующих ТЭГ.

Новая идея состоит в использовании для повышения коэффициента термоэдс $S$ эффекта увлечения электронов потоком тепла - фононами в тонких пленках.

Уникальным материалом, в котором реализуется указанная идея, является углеродная наноструктура, которая состоит как из области с $s p^{2}$-гибридизацией атомов углерода, графитоподобной области с металлическими свойствами, так и из области с $s p^{3}$-гибридизацией атомов углерода, представляющей собой алмазоподобную область с диэлектрическими свойствами. В такой наноструктуре, как показано ранее $[1,2]$, должен реализоваться эффект увлечения электронов баллистическими - не сталкивающимися друг с другом - фононами. В идеальных условиях это позволяет достичь величины $S \approx 1.50 \mathrm{mV} \cdot \mathrm{K}^{-1}$. Указанная углеродная наноструктура защищена патентом РФ [3].

На этой основе был предложен вариант реализации ТЭГ с рекордными параметрами [6]. Цель настоящей работы показать, что технологически возможно создать такие углеродные наноструктуры, при применении которых предложенный вариант реализации ТЭГ с рекордными параметрами будет экспериментально достижим.
В различных способах получения пленок - слоев графитоподобного $\left(s p^{2}\right)$ материала с высоким кристаллическим совершенством - температуры синтеза или последующего отжига обычно составляют $1000^{\circ} \mathrm{C}$ и выше. Такие значения температуры превышают типичную температуру CVD-роста (CVD - chemical vapor deposition) алмазных пленок на разных подложках, что может привести к изменениям фазового состава и нарушениям механических свойств $s p^{3}$-слоя из-за термического воздействия в процессе осаждения на него $s p^{2}$-слоя. Для достижения технологической совместимости процессов осаждения чередующих слоев с $s p^{3}$ и $s p^{2}$-гибридизацией атомов углерода были исследованы технологические схемы получения графитоподобных материалов - $s p^{2}$-слоев - при температурах, не превышающих используемые в процессе CVD-роста $s p^{3}$-слоев.

B качестве метода осаждения графитоподобных пленок применен метод магнетронного распыления графитовой мишени в режиме постоянного тока.

Измерения толщины пленок $s p^{2}$-материала (20-140 nm) проведены методами сканирующей электронной микроскопии (СЭМ), зондовой профилометрии и сканирующей зондовой микроскопии. Результаты совпадают. Метод СЭМ не позволил надежно определять толщины менее $20 \mathrm{~nm}$.

Было проведено исследование технологических схем нанесения чередующихся слоев $s p^{3}$ (основного материала термоэлемента, ОМ) и $s p^{2}$ (дополнительного материла термоэлемента, ДМ).

Было проведено последовательное осаждение слоя $s p^{3}$ методом микроволнового плазмохимического газофазного осаждения (MWPCVD) при низких концентрациях метана в рабочей смеси $(<1 \%)$. Далее осаждался слой $s p^{2}$ материала тем же методом MWPCVD при высоких 
концентрациях метана (> 10\%). Затем осаждался слой $s p^{3}$ методом MWPCVD при низких концентрациях метана в рабочей смеси $(<1 \%)$.

Для проведения структурных исследований трехслойных материалов из чередующихся пленок ОМ и ДМ применялся метод СЭМ, с помощью которого получались изображения поперечного сечения структур на различных этапах их создания. На рис. 1 в качестве примера реализованной схемы выращивания многослойных структур методом MWPCVD приведены изображения поперечного сечения: слоя $s p^{3}$ на кремниевой подложке $(a)$, слоя $s p^{2}$ на слое $s p^{3}(b)$ и трехслойной структуры $s p^{3}-s p^{2}-s p^{3}(c)$. В многослойных структурах толщины слоев $s p^{3}$ составляли $160-310 \mathrm{~nm}$, толщины слоев $s p^{2}-$ 40-150 nm.

Таким образом, в данной схеме осуществлен рост $s p^{3}$-слоев на слоях с высоким содержанием $s p^{2}$-углерода. Сообщений в литературе об осуществлении такого процесса авторами не найдено. Проведенные исследования технологических схем получения чередующихся пленок ОМ и ДМ показали возможность практической реализации структур с тремя и более чередующимися слоями при создании термоэлектрического преобразователя.

Для измерения термоэлектрических характеристик использовалась простейшая двухслойная система. Для этого проводилось выращивание на кварцевой подложке размером $16 \times 16 \mathrm{~mm} s p^{3}$ (алмазного)-слоя, затем было проведено нанесение системы золотых контактов методом фотолитографии, после этого на золотые контакты был нанесен рабочий слой - графитоподобная пленка с зонами нагрева и охлаждения по краям (рис. 2). Для создания измерительной установки оказалось необходимым провести разварку и корпусирование полученного двухслойного образца. Затем на поверхности корпусированной подложки с $s p^{3} / s p^{2}$-слоями и стержневыми выводами контактов разваренной подложки закреплялась покрывающая кварцевая пластина. Вся система скреплялась прижимными пластинами.

Нагрев образца на $250-300^{\circ} \mathrm{C}$ обеспечивался с одной из сторон пластины с помощью контактного нагревателя (паяльника). Температура нагревателя измеряется термопарой. Охлаждение обеспечивалось прижимаемым медным стержнем, погруженным в воду. Температура охлаждаемой части измеряется пирометром. Типичные результаты измерения термоэдс при толщине $s p^{2}$-слоя $\sim 100 \mathrm{~nm}$ на поверхности алмаза составили величину, в десятки и сотни раз бо́льшую значения $3 \cdot 10^{-5} \mathrm{mV} \cdot \mathrm{K}^{-1}$, типичного для макроскопического пиролитического графита [7]. Влияние $s p^{3}$-подслоя при такой толщине $s p^{2}$ было гораздо слабее и не превышало $150 \%$. Очевидно, что алмазный подслой обеспечивает увеличение термоэдс элемента. Полученные значения сильно зависят от местоположения контактов, однако эффект наблюдался везде. Трудности реализации достаточно резкого переходного слоя - интерфейса между слоями углерода c $s p^{2}$ - и $s p^{3}$-гибридизацией электронных оболочек (на уровне $\sim 10 \mathrm{~nm})$ - очевидны.
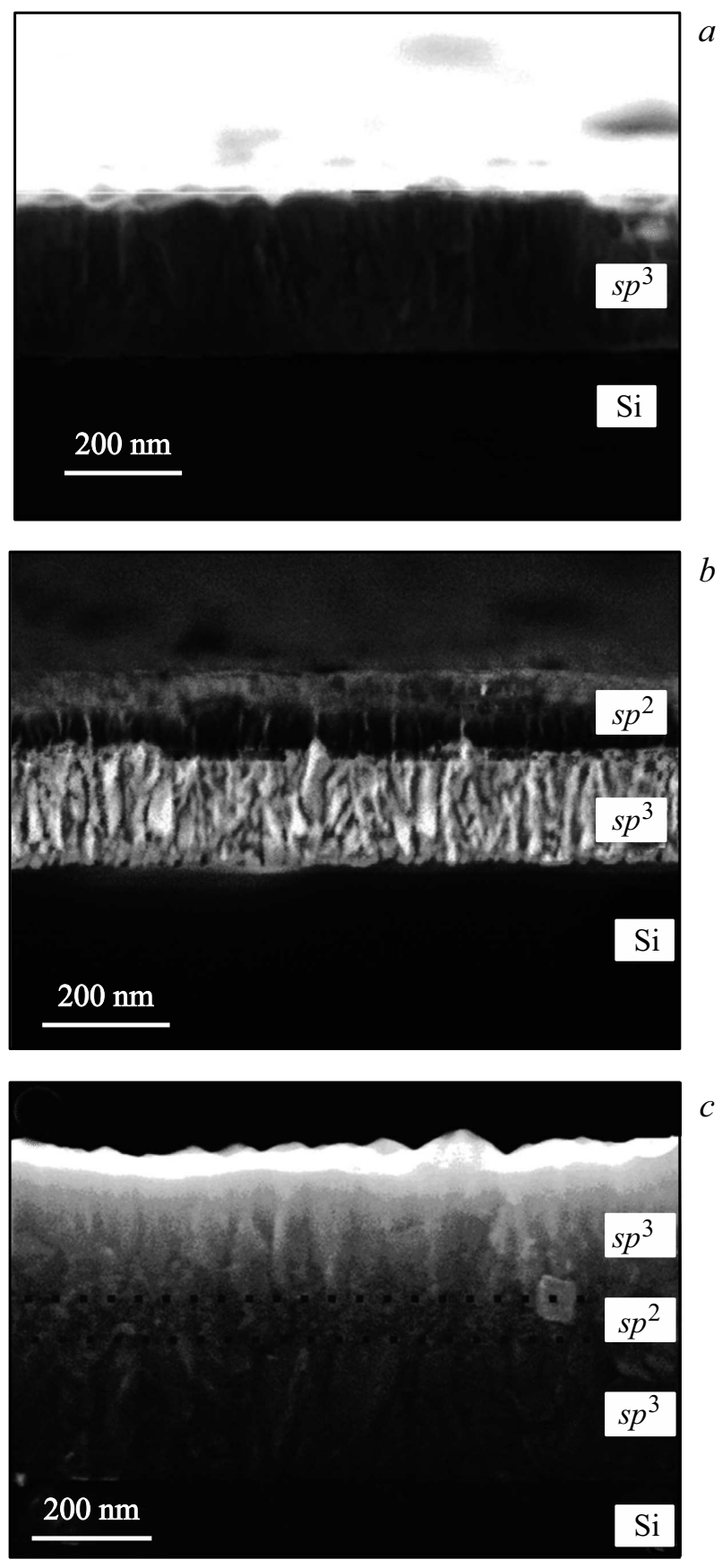

Рис. 1. Полученные методом СЭМ изображения поперечного сечения слоя $s p^{3}(a)$, слоя $s p^{2}$ на $s p^{3}(b)$, трехслойной структуры $s p^{3}-s p^{2}-s p^{3}(c)$.

Конструкция ТЭГ на основе слоистых углеродных структур защищена патентом [8], относящимся к термоэлектрическому приборостроению. Свойственное только углеродным наноструктурам уникальное сопряжение этих материалов на чрезвычайно близких расстояниях создает возможность отвода из $s p^{2}$-областей фононов, испущенных электронами после совместного движения, и позволяет ожидать получение коэффициента термоэдс около $0.1 \mathrm{mV} \cdot \mathrm{K}^{-1}$. 


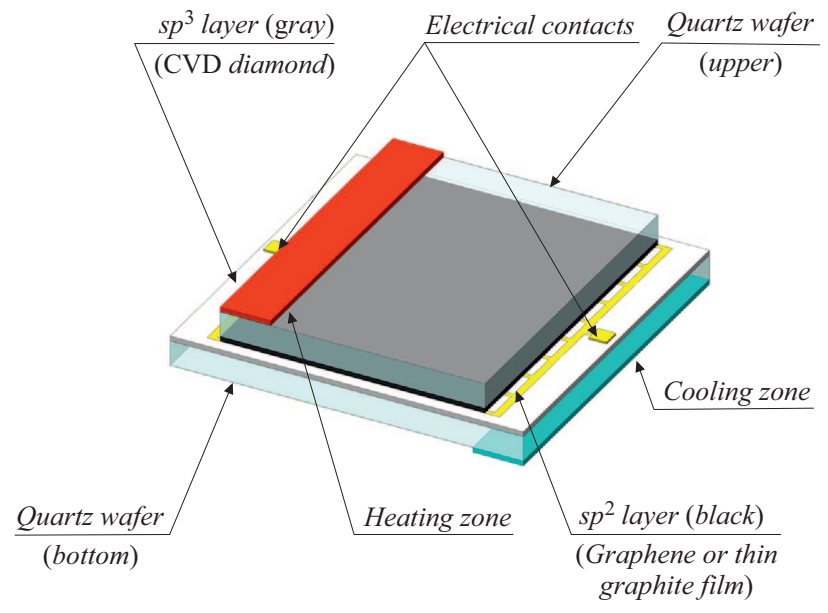

Pис. 2. Двухслойная система, использованная в эксперименте: $s p^{2}$-слой - графитоподобная пленка, получаемая магнетронным напылением; $s p^{3}$-слой - поликристаллический CVDалмаз.

На рис. 2 представлена структура, состоящая из областей двух типов, в одной из которых атомы углерода имеют $s p^{2}$-гибридизацию, а в другой $-s p^{3}$-гибридизацию, т.е. структура, состоящая из графитоподобной и алмазоподобной областей. Алмазоподобная область является своеобразным „холодильником“, отводит тепло от графитоподобной области. Между $s p^{2}$ и $s p^{3}$-областями устанавливается разность температур, протекает поток фононов. Таким образом, поток фононов увлекает электронный газ в $s p^{2}$-области и создает термоэлектрическое поле.

Расчет эффективности процесса увлечения и коэффициента термоэдс, определяемого эффектом увлечения [1], показал, что коэффициент термоэдс на порядки превышает известные значения коэффициента термоэдс для графита, равные $\sim 10-20 \mu \mathrm{V} \cdot \mathrm{K}^{-1}$ в области температур выше комнатной.

Коэффициент термоэдс $S$ может быть записан как $S=\alpha k_{\mathrm{B}} / e$, где $k_{\mathrm{B}}-$ постоянная Больцмана, $e-$ заряд электрона. Величина $\alpha-$ безразмерный коэффициент термоэдс. Очевидно, что смещения электрона $\lambda$ при увлечении баллистическими фононами гораздо больше, чем при увлечении хаотическими. Такие смещения примерно равны или меньше постоянной решетки для графита $(0.35 \mathrm{~nm})$. С другой стороны, очевидно (см. [6]), что баллистическое увлечение возможно только на расстояниях, сравнимых с длиной пробега фонона. В настоящее время технологически достижима толщина $s p^{2}$ слоя, бо́льшая чем $50 \mathrm{~nm}$. Имеем (см. [1])

$$
\alpha_{b a l} \cong\left(\frac{2 \pi k_{\mathrm{B}} T \lambda}{h c}\right)^{3} \text {. }
$$

Числовой множитель принят равным единице ( $c \approx 1.5 \cdot 10^{3} \mathrm{~m} / \mathrm{s}-$ скорость звука в $s p^{2}$-области, $h-$ постоянная Планка). Оценки показывают, что коэффициент термоэдс $\alpha \approx \alpha_{b a l}=600-700$ при температурах
$T \approx 3 \cdot 10^{2} \mathrm{~K}$. Это означает, что коэффициент термоэдс $S \approx 50 \mathrm{mV} \cdot \mathrm{K}^{-1}$. Примем, что электропроводность $s p^{2}$ пленки совпадает с табличной величиной, приводимой в справочниках для угольных электродов $(\sigma \approx 2500 \mathrm{~S})$, а теплопроводность тонких $s p^{2}$-слоев значительно превышает справочную теплопроводность графита и равна $\chi \approx 200 \mathrm{~W} /(\mathrm{m} \cdot \mathrm{K})$ [7]. Эффективность термоэлектрического генератора $Z T=T S^{2} \sigma / \chi$ зависит от теплопроводности материала $\chi$, его электропроводности $\sigma$ и коэффициента термоэдс $S$. Тогда термоэлектрическая эффективность рассмотренной системы может достигать $Z T \approx 20$ при комнатной температуре. В лучших из существующих ТЭГ $[1,4]$ термоэлектрическая эффективность $Z T \approx 1.5$ при комнатной температуре.

Можно сделать следующий вывод: идею, состоящую в использовании для повышения коэффициента термоэдс $S$ эффекта увлечения электронов потоком тепла (фононами), возможно реализовать! Размещение графитоподобного материала на алмазоподобной пленке также обеспечивает рост значения термоэдс. В этом, на наш взгляд, проявляется эффект баллистического увлечения электронов фононами.

Можно ожидать, что технологически осуществимо создание таких углеродных наноструктур, при применении которых предложенный вариант реализации ТЭГ с рекордными параметрами будет экспериментально достижим.

Авторы благодарят А.Я. Вуля, В.Г. Голубева, С.В. Коняхина, Ф.М. Шахова, С.В. Кидалова, А.П. Мейлахса за помощь и обсуждение, Н.Д. Ильинскую и ее сотрудников за проведение литографических работ, О.Н. Сараева и его сотрудников за проведение разварки контактов.

Работа выполнена при поддержке РНФ (грант 16-1900075).

\section{Список литературы}

[1] Eidelman E.D., Vul' A.Ya. // J. Phys.: Condens. Matter. 2007. V. 19. N 26. P. 266210. DOI: http://dx.doi.org/10.1088/0953$8984 / 19 / 26 / 266210$

[2] Koniakhin S.V., Eidelman E.D. // Europhys. Lett. 2013. V. 103. N 3. P. 37006. DOI: http://dx.doi.org/10.1209/0295$5075 / 103 / 37006$

[3] Вуль А.Я., Эйдельман Е.Д. Патент РФ № 2376681. Термоэлектрический элемент. Приоритет от 06.10.2008.

[4] Kubakaddi S.S., Bhargavi K.S. // Phys. Rev. B. 2010. V. 82. N 15. P. 155410.

DOI: https://link.aps.org/doi/10.1103/PhysRevB.82.155410

[5] Koniakhin S.V., Nalitov A.V. // Phys. Rev. B. 2016. V. 94. N 12. P. 125403. DOI: http://dx.doi.org/10.1103/PhysRevB.94.125403

[6] Эйдельман Е.Д. // ФТП. 2017. Т. 51. В. 7. С. 944-947.

[7] Kidalov S.V., Shakhov F.M., Vul' A.Y., Ozerin A.N. // Diamond Relat. Mater. 2010. V. 19. N 7-9. P. 976-980. DOI: http://dx.doi.org/10.1016/j.diamond.2010.03.004

[8] Эйдельман Е.Д., Шахов Ф.М., Вуль А.Я. Патент РФ № 2628676. Термоэлектрический элемент. Приоритет от 25.11.2016. 